\title{
The Influence of the Amundsen-Bellingshausen Seas Low on the Climate of West Antarctica and Its Representation in Coupled Climate Model Simulations
}

\author{
J. Scott Hosking, Andrew Orr, Gareth J. Marshall, John Turner, And Tony Phillips \\ British Antarctic Survey, Natural Environment Research Council, Cambridge, United Kingdom
}

(Manuscript received 16 November 2012, in final form 27 February 2013)

\begin{abstract}
In contrast to earlier studies, the authors describe the climatological deep low pressure system that exists over the South Pacific sector of the Southern Ocean, referred to as the Amundsen-Bellingshausen Seas low (ABSL), in terms of its relative (rather than actual) central pressure by removing the background areaaveraged mean sea level pressure (MSLP). Doing so removes much of the influence of large-scale variability across the ABSL sector region (e.g., due to the southern annular mode), allowing a clearer understanding of ABSL variability and its effect on the regional climate of West Antarctica. Using ECMWF Interim ReAnalysis (ERA-Interim) fields, the annual cycle of the relative central pressure of the ABSL for the period from 1979 to 2011 shows a minimum (maximum) during winter (summer), differing considerably from the earlier studies based on actual central pressure, which suggests a semiannual oscillation. The annual cycle of the longitudinal position of the ABSL is insensitive to the background pressure, and shows it shifting westward from $\sim 250^{\circ}$ to $\sim 220^{\circ} \mathrm{E}$ between summer and winter, in agreement with earlier studies. The authors demonstrate that ABSL variability, and in particular its longitudinal position, play an important role in controlling the surface climate of West Antarctica and the surrounding ocean by quantifying its influence on key meteorological parameters. Examination of the ABSL annual cycle in 17 CMIP5 climate models run with historical forcing shows that the majority of them have definite biases, especially in terms of longitudinal position, and a correspondingly poor representation of West Antarctic climate.
\end{abstract}

\section{Introduction}

The Amundsen-Bellingshausen Seas low (ABSL) is a quasi-stationary area of climatological low pressure that exists over the South Pacific sector of the Southern Ocean between the Antarctic Peninsula and the Ross Sea (see Fig. 1 for a map of the region). The ABSL is present because of the large number of synoptic-scale and subsynoptic-scale low pressure systems in this sector of the circumpolar trough (Fogt et al. 2012b). Both the topographical and geographical asymmetry of the Antarctic continent (Lachlan-Cope et al. 2001) contribute to the enhanced baroclinicity required for the formation and intensification of such disturbances (Walsh et al. 2000). The minimum mean sea level pressure (MSLP) associated with the ABSL is characterized by large seasonal variability in both location

Corresponding author address: J. Scott Hosking, British Antarctic Survey, Natural Environment Research Council, High Cross, Madingley Road, Cambridge CB3 0ET, United Kingdom.

E-mail: jask@bas.ac.uk and central pressure (Fogt et al. 2012b; Turner et al. 2013b).

ABSL variability strongly influences the climate of West Antarctica by controlling the meridional component of the large-scale atmospheric circulation, with consequences for 10-m meridional wind velocity (V10), near-surface $(2 \mathrm{~m})$ air temperature (hereafter referred to as SAT), precipitation (PPN), and sea ice concentration (SIC) (e.g., Turner et al. 2009; Küttel et al. 2012). For example, the circulation driven by a persistent and deep ABSL over the Amundsen-Bellingshausen Seas (ABS) sector will be an enhanced northerly airflow across the western Antarctic Peninsula sector, resulting in intrusions of marine air, causing higher SAT and PPN over West Antarctica (Vaughan et al. 1999; Schneider et al. 2012) and reduced sea ice extent (SIE, where SIC fraction is at least 0.15) in the Bellingshausen and eastern Amundsen Seas (Massom et al. 2008). Conversely, the enhanced southerly flow of cold continental air along the western flank of the ABSL will result in increased SIE in the western Amundsen and Ross Seas (Massom et al. 2008). Consistent with the large variability of the ABSL, these 


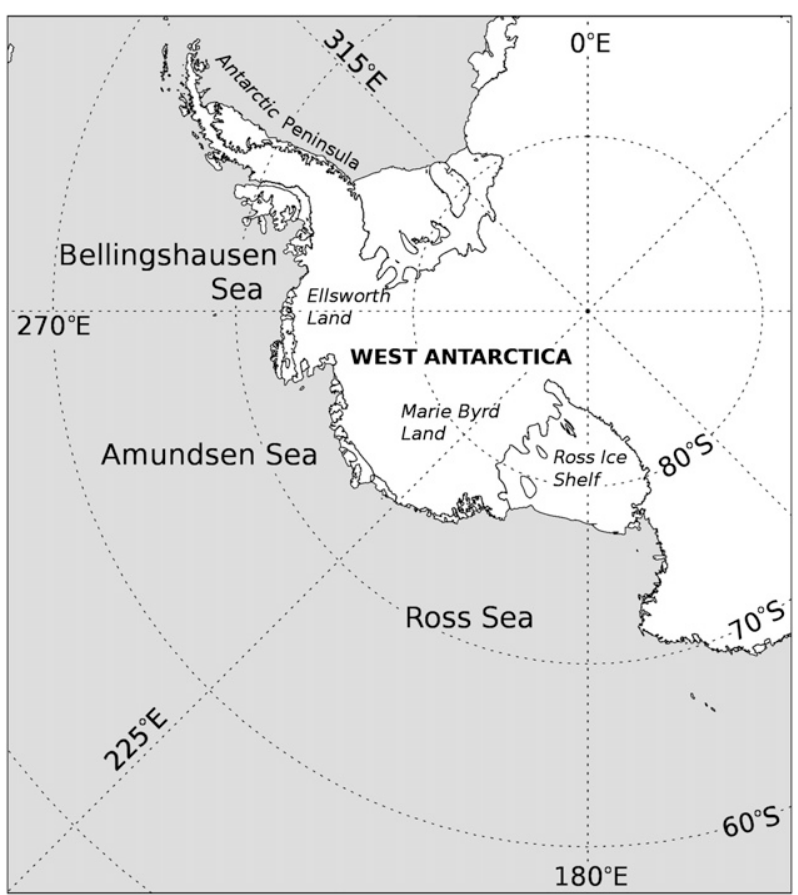

FIG. 1. Map showing the region of the Southern Ocean where the Amundsen-Bellingshausen Seas low is located. The locations of the Bellingshausen, Amundsen, and Ross Seas are marked, as well as that of the Ross Ice Shelf. Also marked are the regions of Ellsworth Land and Marie Byrd Land, West Antarctica, and the Antarctic Peninsula, which border them.

key climatic parameters are similarly characterized by considerable interannual variability (e.g., Zwally et al. 2002; Monaghan et al. 2006, 2008).

Previous studies have shown that the circulation in the ABSL sector region is strongly influenced by large-scale patterns of atmospheric variability, such as the southern annular mode (SAM) and El Niño-Southern Oscillation (ENSO) (e.g., Kwok and Comiso 2002; Turner 2004). The SAM is the dominant mode of atmospheric variability around Antarctica, essentially describing the north-south pressure gradient and the associated strength of the circumpolar zonal winds (e.g., Thompson and Wallace 2000). However, the SAM is additionally characterized by a significant nonannular component in the ABSL area (Lefebvre et al. 2004; Fogt et al. 2012a). During ENSO events, a Rossby wave train of alternating positive and negative geopotential height anomalies [the Pacific-South American (PSA) pattern] becomes established from the central Pacific to the ABS region. It has been further demonstrated that the ENSO teleconnection in the ABS region is modulated by strong SAM events (Fogt et al. 2011).

Significant regional climate change has occurred on the western coast of the Antarctic Peninsula, which has undergone the largest recorded SAT increase across the Southern Hemisphere in recent decades (Vaughan et al. 2001). However, the extent to which this warming extends into West Antarctica and the significance of these changes is difficult to determine due to the paucity of long in situ records. Recent reconstructions of Antarctic SAT suggest that West Antarctica has probably warmed since the 1950s (Steig et al. 2009; O'Donnell et al. 2011), but there is disagreement in the spatial extent, seasonality, and magnitude of the trends. Perhaps the most persuasive evidence is a recently compiled reconstruction of SAT for Byrd Station in central West Antarctica $\left(80^{\circ} \mathrm{S}\right.$, $120^{\circ} \mathrm{W}$ ), which revealed an annually averaged warming rate of $\sim 0.5^{\circ} \mathrm{C}$ decade $^{-1}$ between 1958 and 2010, substantially greater than the global average (Bromwich et al. 2013). Pronounced warming of this region over the past $\sim 100$ years has also been detected from ice cores (Schneider and Steig 2008). Recent regional sea ice change reflects further evidence of significant climate change in this region. Over the last few decades opposing trends in SIE have occurred in the ABS (decline) and Ross Sea (advance) sectors (e.g., Zwally et al. 2002; Stammerjohn et al. 2008; Turner et al. 2009). Trends in snowfall over West Antarctica are generally not thought to be statistically significant (Monaghan et al. 2006), although some reanalysis datasets suggest an increase in precipitation over Ellsworth Land over the last few decades (Bromwich et al. 2011), consistent with a recent rapid increase in PPN found in the southwestern Antarctic Peninsula (Thomas et al. 2008).

Recent studies have showed that trends in geopotential height and near-surface winds in the ABSL sector region are consistent with such changes (e.g., Turner et al. 2009; Ding et al. 2011; Schneider et al. 2012; Fogt et al. 2012b; Holland and Kwok 2012). Owing to its proximity, such circulation changes could be consistent with shifts in the strength and location of the ABSL. In particular, Fogt et al. (2012b) showed that ABSL variability is significantly linked to the SAM, which over the last few decades has shown a significant trend toward a more positive phase during summer and autumn (e.g., Marshall 2003). Moreover, given this connection, the ability of coupled atmosphere-ocean climate models to represent the present climate of West Antarctica, and by extension provide evidence for their suitability to simulate its future climate (e.g., Connolley and Bracegirdle 2007), would clearly depend on how well they represent ABSL variability.

However, before such links can be made, more work is needed to better understand the connection between the position and strength of the ABSL and the wind patterns in the region, and thus the overall impact on SAT, PPN, and SIE in the region of West Antarctica. To fully 
understand this, the underlying changes to the regional circulation resulting from modes of large-scale variability must first be removed. This is the objective of this study. To do this we develop indices (hereafter described as an index, although it comprises two parts) that describe the strength and location of the ABSL, with its strength measured in terms of its relative (rather than actual) central pressure by removing the effect of largescale pressure variability. This not only gives a clearer understanding of ABSL variability, which has effectively been detrended, but also allows us to properly quantify the influence of the ABSL on the regional climate of West Antarctica. In addition, we investigate the representation of ABSL variability (as well as the associated representation of West Antarctic climate) in the set of climate models participating in phase 5 of the Coupled Model Intercomparison Project (CMIP5; Taylor et al. 2012), as used in the Intergovernmental Panel on Climate Change (IPCC) Fifth Assessment Report (AR5).

The study is laid out as follows. Section 2 describes the various forms of data used and the methodology used to compute the ABSL index. Section 3 examines the annual cycle of the mean state and interannual variability of our ABSL index for the period since 1979. The relationship between the index and the surface climate of West Antarctica is considered in section 4. In section 5 we assess the representation of the annual cycle of the ABSL in the CMIP5 models. Section 6 presents a discussion and documents the conclusions of the study.

\section{Data and methods}

\section{a. Reanalysis data}

The European Centre for Medium-Range Weather Forecasts (ECMWF) Interim Re-Analysis (ERA-Interim; Dee et al. 2011) monthly fields of MSLP, SAT, V10, and PPN from 1979 to 2011 (a 33-yr period) were used. ERAInterim was produced using the ECMWF Integrated Forecast System with a horizontal resolution of T255 (N128, 80-km grid spacing), 60 vertical levels, and a model top of $0.1 \mathrm{hPa}$. Observations were assimilated using a 12-h four-dimensional variational analysis with output every $6 \mathrm{~h}$. In a recent study, Bracegirdle and Marshall (2012) determined that ERA-Interim was the most accurate of six different reanalysis datasets when verified over Antarctica against independent surface and midtropospheric pressure and temperature in situ observations, including buoy data from the Bellingshausen Sea. All calculations used data obtained at a horizontal resolution of T159 (N80, 125-km grid spacing). Additionally, the Hadley Centre Sea Ice and Sea Surface Temperature dataset, version 1 (HadISST1;
Rayner et al. 2003), monthly fields of sea surface temperature (SST) on a $1^{\circ}$ latitude-longitude grid for the period 1979-2011 were also used.

\section{b. Sea ice concentration data}

Satellite-derived (Comiso 1999) monthly fields of sea ice concentration (SIC) at $\sim 25 \mathrm{~km}$ grid spacing from 1979 to 2011 were used.

\section{c. Climate model data}

CMIP5 monthly fields of MSLP, SAT, V10, PPN, and SIC from simulations of the twentieth century with all forcings (hereafter "historical" runs) from 1979 to 2005 (a 27-yr period) were used. Only data up to 2005 are utilized as this marks the end of the CMIP5 historical runs. Table 1 lists the 17 CMIP5 models used in the study and the number of realization runs (ensemble members) in each. For multiensemble models we use all available realizations. In the historical runs the models are forced by observed changes in atmospheric composition owing to both anthropogenic and volcanic influences, and solar variability. All calculations used data obtained on the distinct native model grid of each model.

\section{d. The ABSL index}

ABSL variability can be quantified by developing an index that characterizes its location and strength. In previous studies this was achieved by determining the location and magnitude of the actual central pressure (minimum MSLP) in the ABSL region (Fogt et al. 2012b; Turner et al. 2013b). For example, the mean seasonal patterns of MSLP for the ABSL region (using ERAInterim data from 1979 to 2011) are shown in Figs. 2a-d. From this, an index based on actual central pressure shows the greatest ABSL depth during spring.

In this study we define an ABSL index based on the effects of changes in central pressure relative to the background pressure representative of large-scale variability in the ABSL region. The representative background pressure is calculated by averaging the MSLP over the region defined as $60^{\circ}-75^{\circ} \mathrm{S}, 170^{\circ}-290^{\circ} \mathrm{E}\left(170^{\circ} \mathrm{E}-\right.$ $070^{\circ} \mathrm{W}$ ) (indicated by the boxes in Figs. 2e-h; hereafter referred to as the ABSL sector region). This value is subtracted from the actual MSLP field to give the relative pressure within the ABSL sector region (i.e., the regional pressure anomaly). For example, Figs. 2e-h are analogous to Figs. 2a-d but show the equivalent relative MSLP for the ABSL region (using ERA-Interim data from 1979 to 2011). From this, an index based on relative central pressure (relative minimum MSLP) shows the greatest ABSL depth during winter.

Our revised index describes the location and magnitude of the relative central pressure. This calculation is 
TABLE 1. Model, number of realizations, and the rms deviation (RMSD) and rank in terms of both ABSL longitude and relative central pressure of the CMIP5 models used in this study. The corresponding multimodel mean is computed by averaging the RMSD of all 17 models.

\begin{tabular}{|c|c|c|c|}
\hline Model & $\begin{array}{l}\text { No. of } \\
\text { realizations }\end{array}$ & $\begin{array}{l}\text { RMSD (and rank) in } \\
\text { terms of ABSL } \\
\text { lon }\left(^{\circ}\right)\end{array}$ & $\begin{array}{l}\text { RMSD (and rank) in } \\
\text { terms of ABSL relative } \\
\text { central pressure }(\mathrm{hPa})\end{array}$ \\
\hline Community Climate System Model, version 4 (CCSM4) & 6 & $6.5(1)$ & $0.86(7)$ \\
\hline $\begin{array}{l}\text { Centre National de Recherches Météorologiques Coupled Global Climate } \\
\text { Model, version } 5 \text { (CNRM-CM5) }\end{array}$ & 9 & $9.2(3)$ & $0.87(8)$ \\
\hline $\begin{array}{l}\text { Commonwealth Scientific and Industrial Research Organisation Mark } \\
\text { 3.6.0 (CSIRO-Mk3.6.0) }\end{array}$ & 10 & $22.6(17)$ & $0.92(9)$ \\
\hline $\begin{array}{l}\text { Goddard Institute for Space Studies Model E, coupled with the } \\
\text { Hybrid Coordinate Ocean Model (HYCOM) (GISS-E2-H) }\end{array}$ & 6 & $14.1(13)$ & $1.30(14)$ \\
\hline $\begin{array}{l}\text { Goddard Institute for Space Studies Model E, coupled with the } \\
\text { Russell ocean model (GISS-E2-R) }\end{array}$ & 2 & $11.6(10)$ & $0.74(3)$ \\
\hline Hadley Centre Coupled Model, version 3 (HadCM3) & 10 & $18.1(15)$ & $0.97(12)$ \\
\hline $\begin{array}{l}\text { Hadley Centre Global Environmental Model, version 2, Carbon Cycle } \\
\text { (HadGEM2-CC) }\end{array}$ & 1 & $11.5(9)$ & $0.83(5 / 6)$ \\
\hline $\begin{array}{l}\text { Hadley Centre Global Environmental Model, version 2, Earth System } \\
\text { (HadGEM2-ES) }\end{array}$ & 4 & $9.6(4)$ & $0.64(1)$ \\
\hline Institute of Numerical Mathematics Coupled Model, version 4 (INM-CM4) & 1 & $21.7(16)$ & $0.70(2)$ \\
\hline $\begin{array}{l}\text { L'Institut Pierre-Simon Laplace Coupled Model, version 5, coupled with } \\
\text { Nucleus for European Modelling of the Ocean (NEMO), low resolution } \\
\text { (IPSL-CM5A-LR) }\end{array}$ & 4 & $14.3(14)$ & $0.83(5 / 6)$ \\
\hline $\begin{array}{l}\text { Model for Interdisciplinary Research on Climate Earth System Model } \\
\text { (MIROC-ESM) }\end{array}$ & 3 & $13.8(12)$ & $1.29(13)$ \\
\hline $\begin{array}{l}\text { Model for Interdisciplinary Research on Climate, with chemistry } \\
\text { (MIROC-ESM-CHEM) }\end{array}$ & 1 & $12.3(11)$ & $1.54(16)$ \\
\hline Model for Interdisciplinary Research on Climate, version 4h (MIROC4h) & 3 & $10.3(5)$ & $0.75(4)$ \\
\hline Model for Interdisciplinary Research on Climate, version 5 (MIROC5) & 1 & $11.3(7)$ & $0.96(11)$ \\
\hline Max Planck Institute Earth System Model, low resolution (MPI-ESM-LR) & 3 & $11.4(8)$ & $0.94(10)$ \\
\hline $\begin{array}{l}\text { Meteorological Research Institute Coupled General Circulation Model, } \\
\text { version } 3 \text { (MRI-CGCM3) }\end{array}$ & 5 & $8.1(2)$ & $2.46(17)$ \\
\hline Norwegian Earth System Model, intermediate resolution 1M (NorESM1-M) & 3 & $10.7(6)$ & $1.21(15)$ \\
\hline Mean & & 9.0 & 0.50 \\
\hline
\end{tabular}

done for each individual season, creating a seasonal time series of the index. We also calculate a monthly time series of the index using monthly averaged MSLP fields. These data can be found online (at http://www.antarctica. ac.uk/data/absl/). Note that on occasion a second but much smaller minimum was present. If so, the location and relative central pressure of the deepest minimum was selected. Tests showed that the climatological annual cycle of the ABSL index (discussed below) was qualitatively insensitive to whether the secondary minima were chosen instead due to their low occurrence (not shown). Note also that the climatological annual cycle of the ABSL index was insensitive to extending the northern boundary of the chosen ABSL sector region to $55^{\circ} \mathrm{S}$.

Figure $3 \mathrm{a}$ shows the monthly time series of the magnitudes of the ABSL actual central pressure and area-averaged MSLP in the ABSL region during 19902000 using ERA-Interim data. These two time series are clearly related (their correlation is $r \approx 0.9$ for the period from 1979 to 2011), which indicates that the ABSL actual central pressure is strongly modulated by changes in broad-scale variability, such as that associated with the SAM and ENSO. (Note that all correlations are calculated using detrended time series.) Indeed, this is consistent with a statistically significant correlation (at the $<1 \%$ level) between the time series of 1 ) actual central pressure and the SAM index (Marshall 2003; available at http://www.antarctica.ac.uk/met/gjma/sam. html) across all seasons and 2) actual central pressure and the Niño-3.4 index (Trenberth 1997) during summer only (see Table 2). The Niño-3.4 index was calculated using HadISST1 SST data and is based on SST anomalies in the Niño-3.4 region [see Trenberth (1997) for further details]. Figure $3 \mathrm{~b}$ shows the monthly time series of the magnitudes of the ABSL relative central pressure. Comparison with Fig. 3a shows that this time series is in no way linked to the area-averaged MSLP or to the actual central pressure. This confirms that the influence of large-scale variability has been considerably lessened in this ABSL index. Further evidence of the decoupling 

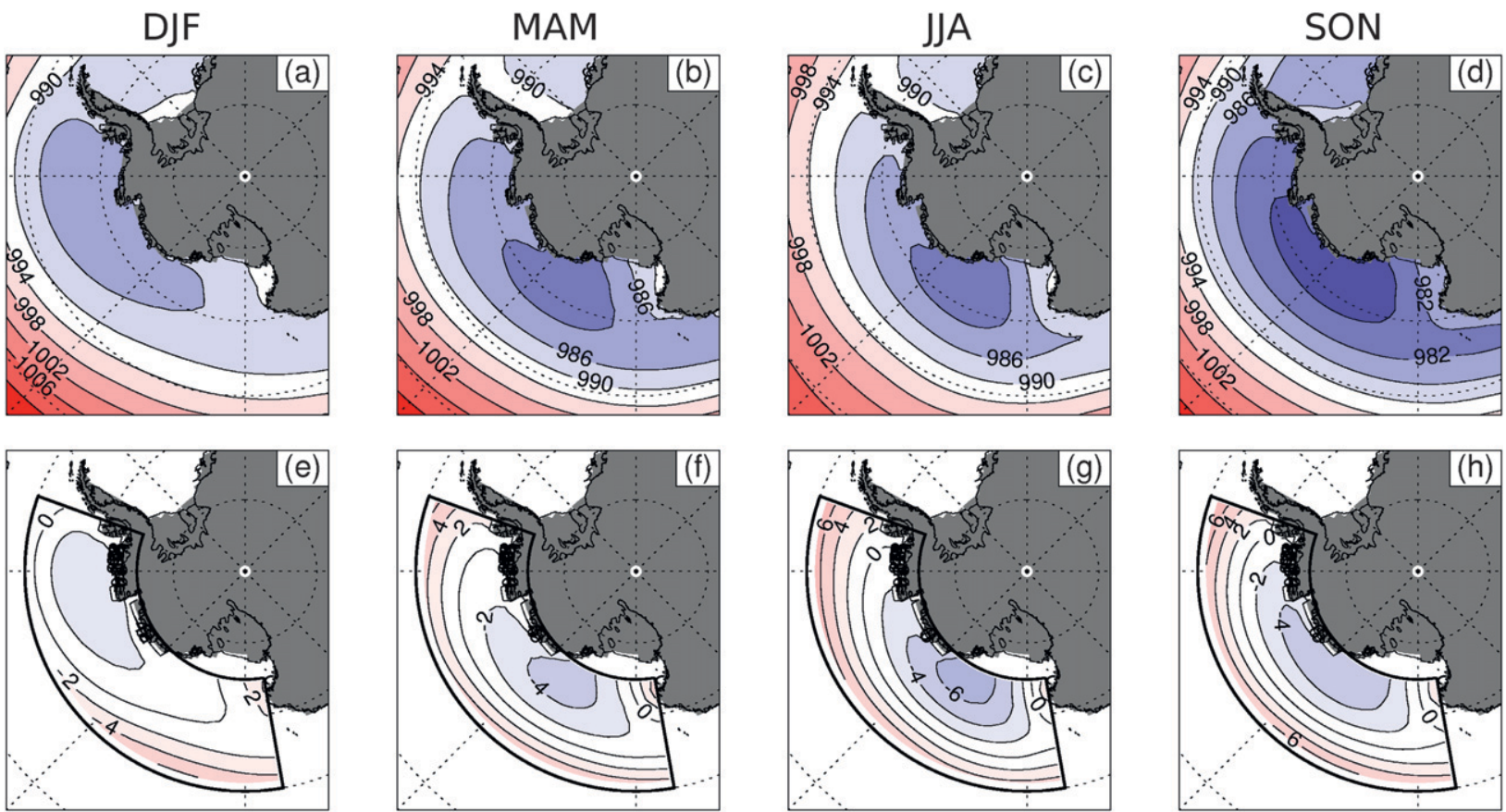

FIG. 2. Seasonal mean MSLP (hPa) over the South Pacific sector of the Southern Ocean for (a) summer [December-February (DJF)], (b) autumn [March-May (MAM)], (c) winter [June-August (JJA)], and (d) spring [September-November (SON)] for ERA-Interim for the period 1979-2011. (e)-(h) As in (a)-(d) but showing the corresponding relative pressure in the ABSL sector region (indicated by the box; $\left.60^{\circ}-75^{\circ} \mathrm{S}, 170^{\circ}-290^{\circ} \mathrm{E}\right)$, computed by subtracting the area-averaged MSLP from the seasonal MSLP field.

between the ABSL and large-scale variability is the absence of any significant correlation between the time series of relative central pressure and the SAM index (see Table 2).

\section{Intra-annual characteristics of the ABSL}

The annual cycle of ABSL relative central pressure for ERA-Interim for the period 1979-2011 is displayed
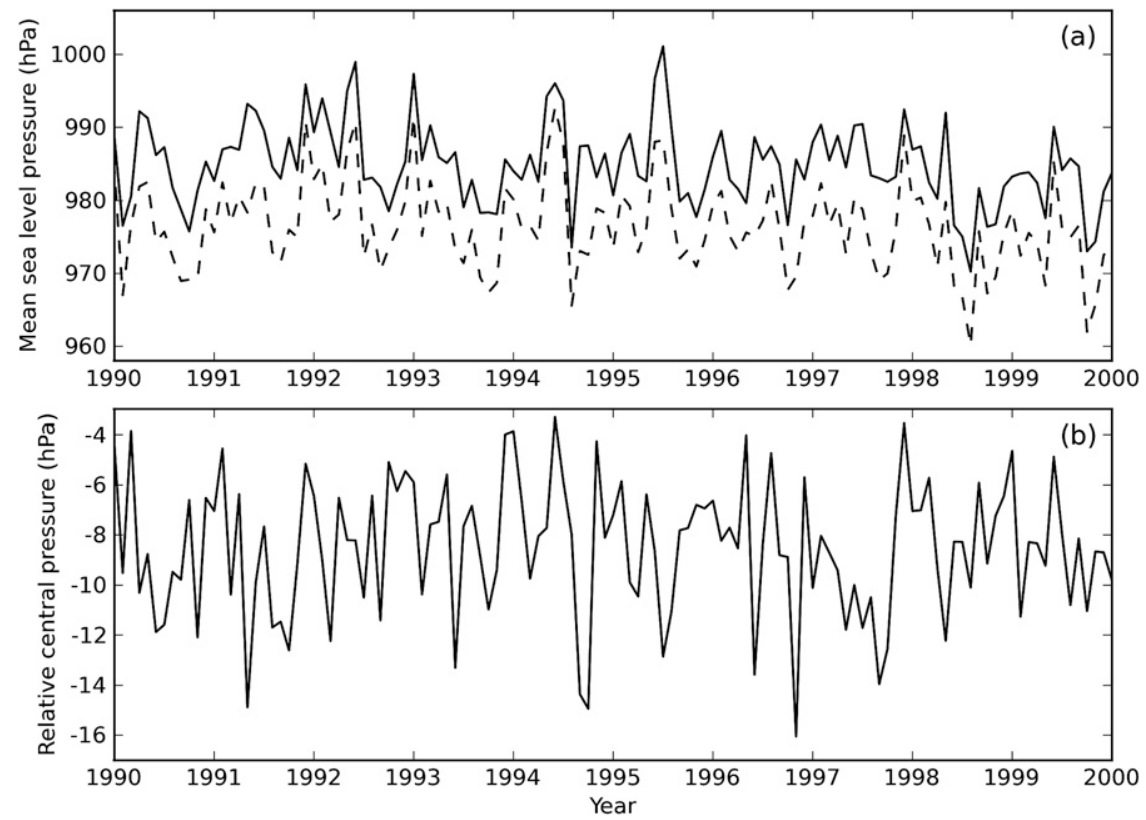

FIG. 3. ERA-Interim time series for the period from 1990 to 2000 for the ABSL sector (indicated by the box in Fig. 2) showing (a) area-averaged MSLP (solid) and actual central pressure (dashed) and (b) relative central pressure $(\mathrm{hPa})$. 
TABLE 2. Correlation of the indices used to define ABSL variability (i.e., actual central pressure, relative central pressure, and longitude) with the SAM index and Niño-3.4 index during summer (DJF), autumn (MAM), winter (JJA), and spring (SON) for ERA-Interim for the period 1979-2011. Statistically significant correlations at $<5 \%(<1 \%)$ are marked by one (two) asterisks.

\begin{tabular}{|c|c|c|c|c|c|c|}
\hline \multirow[b]{2}{*}{ Season } & \multicolumn{3}{|c|}{ SAM } & \multicolumn{3}{|c|}{ Niño 3.4} \\
\hline & $\begin{array}{l}\text { Actual central } \\
\text { pressure }\end{array}$ & $\begin{array}{l}\text { Relative central } \\
\text { pressure }\end{array}$ & Lon & $\begin{array}{l}\text { Actual central } \\
\text { pressure }\end{array}$ & $\begin{array}{c}\text { Relative central } \\
\text { pressure }\end{array}$ & Lon \\
\hline DJF & $-0.78 * *$ & -0.24 & 0.16 & $0.53 * *$ & 0.13 & -0.19 \\
\hline MAM & $-0.57 * *$ & -0.05 & $0.48 * *$ & 0.02 & $-0.36^{*}$ & -0.01 \\
\hline JJA & $-0.75 * *$ & -0.28 & 0.08 & 0.34 & -0.01 & -0.16 \\
\hline SON & $-0.80 * *$ & -0.17 & 0.23 & 0.28 & -0.15 & -0.26 \\
\hline
\end{tabular}

in Fig. 4a and shows a minimum of $-11 \mathrm{hPa}$ during winter (i.e., deepest) and maximum of $-6 \mathrm{hPa}$ in summer (i.e., shallowest). The variability of the ABSL relative central pressure [calculated as one standard deviation $(\sigma)$ of the interannual fluctuations] is least in summer and greatest in winter. This differs considerably from the results of Turner et al. (2013b) and Fogt et al. (2012b), which both suggest a semiannual oscillation (SAO) (i.e., a twice-yearly cycle of intensification and poleward shift of the circumpolar trough during spring and autumn; van Loon 1967) in actual ABSL central pressure with minima or lowest central pressures (maxima or highest central pressures) in autumn and spring (summer and winter). Hence, the ABSL index based on relative central pressure is decoupled from the SAO. As the annual cycle of longitudinal position is insensitive to the background pressure, Fig. 4b shows the mean longitudinal position shifts westward from $\sim 250^{\circ}$ to $\sim 220^{\circ} \mathrm{E}$ between summer and winter, with maximum (minimum) variability during summer (winter), in agreement with Turner et al. (2013b) and Fogt et al. (2012b). Figure 4c shows that the mean latitudinal position of the ABSL shifts south (north) in winter (summer), also in agreement with Turner et al. (2013b) and Fogt et al. (2012b) (i.e., the latitudinal position is also insensitive to background pressure).

To assess the ABSL longitude and relative central pressure together, we plot the seasonal mean of these two quantities for each year from 1979 to 2011 for ERA-Interim in Fig. 5. The only statistically significant relationship (at the $<10 \%$ level) between these two quantities was during summer $(r \approx 0.31)$ and spring
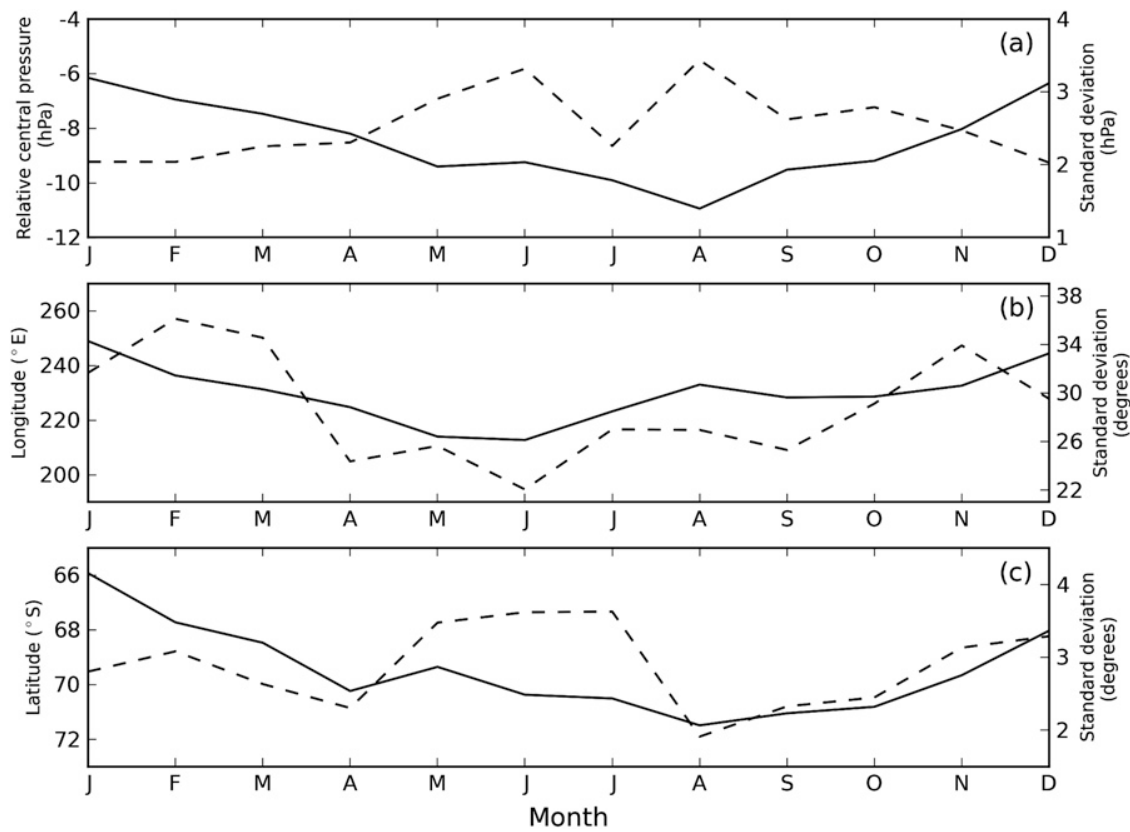

FIG. 4. Mean annual cycle of the monthly ABSL (a) relative central pressure (hPa), (b) longitude $\left({ }^{\circ} \mathrm{E}\right)$, and (c) latitude $\left({ }^{\circ} \mathrm{S}\right)$ for ERA-Interim for the period 1979-2011 (solid). The variability of the data is also shown, calculated as one standard deviation $(\sigma)$ of the interannual fluctuations (dashed). 

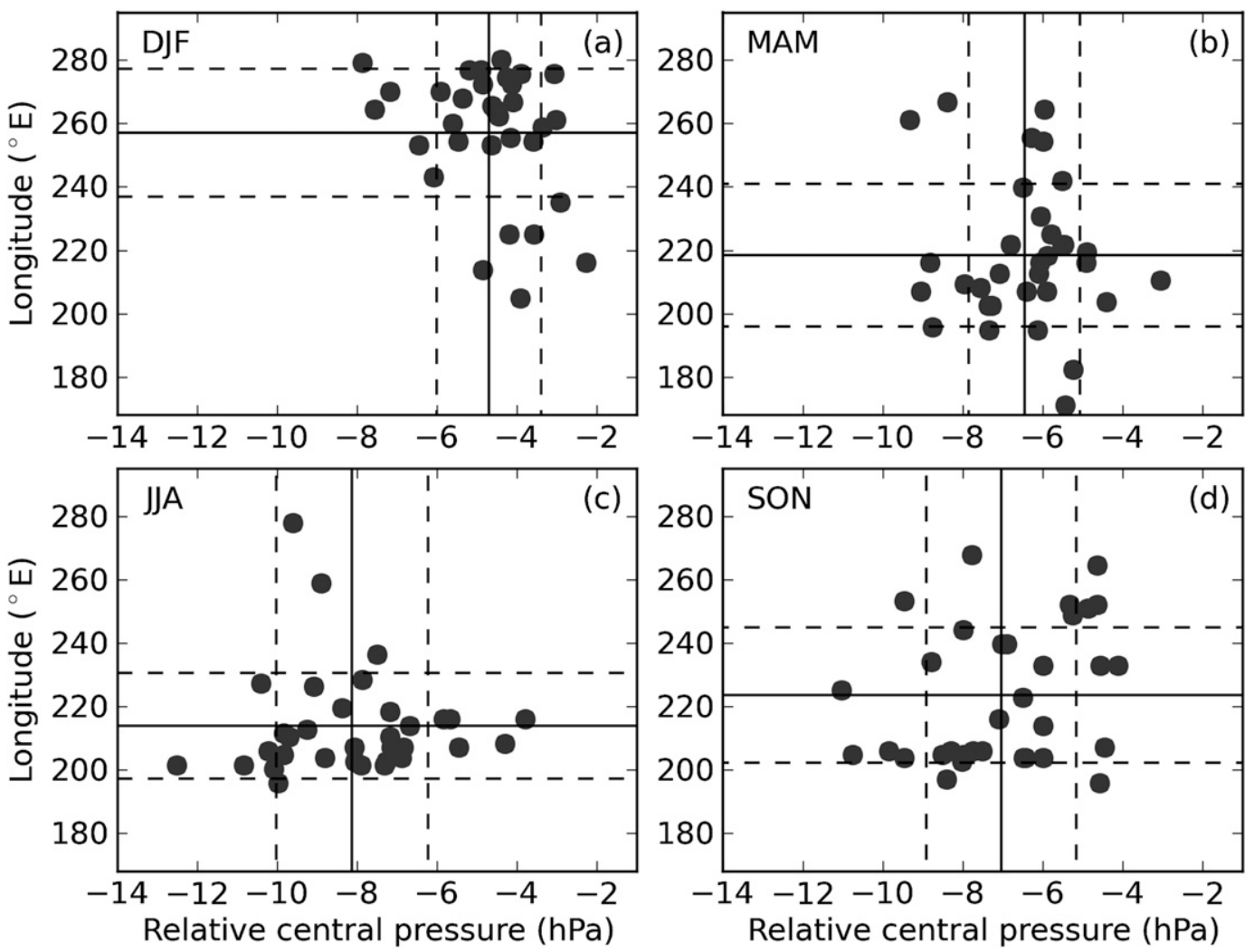

FIG. 5. Scatterplot of the seasonal ABSL longitude $\left({ }^{\circ} \mathrm{E}\right)$ and relative central pressure (hPa) for (a) summer (DJF), (b) autumn (MAM), (c) winter (JJA), and (d) spring (SON) for ERA-Interim for each year for the period from 1979 to 2011. Solid (dashed) lines show the mean (variability) values. The variability is one standard deviation $(\sigma)$ of the interannual fluctuations. Note that as the mean values are weighted toward individual months during which the relative central pressure is deepest, they differ slightly from the corresponding values calculated from the monthly data plotted in Fig. 4.

$(r \approx 0.30)$, which shows that during these seasons the ABSL deepens the farther eastward it is located. Note that, as the seasonal mean values plotted in Fig. 5 are weighted toward individual months during which the relative central pressure is largest, they differ slightly from equivalent values calculated by averaging the monthly data plotted in Fig. 4.

\section{Influence of ABSL variability on the climate of West Antarctica}

To demonstrate the influence of ABSL variability on the surface climate of West Antarctica, seasonal differences of V10, SAT, PPN, and SIC for ERA-Interim are presented based on the ABSL longitude (Fig. 6) and relative central pressure (Fig. 7). For each season the differences were computed by separating the ABSL longitude and relative central pressure for each year of 1979 to 2011 into four quartiles, and presenting composite differences between the lower and upper quartiles (8 yr each). Significance is tested using a two-sided
Student's $t$ test (at the $<5 \%$ level assuming 14 degrees of freedom). Differences are computed as the lower minus the upper quartile so that for relative central pressure (longitude) they are positive when the ABSL is deeper (farther west).

Figure 6 indicates that the largest significant differences in V10 based on ABSL longitude are during autumn and winter and extend over much of coastal West Antarctica and the surrounding ocean, reflecting a strengthening of the northerly (southerly) flow over the Amundsen Sea and eastern Ross Sea (western Ross Sea) when the ABSL is farther west. Coherent with these differences are changes in SAT and PPN, which show warmer and moister (colder and drier) conditions extending considerably far inland, consistent with enhanced onshore maritime (offshore continental) air intrusions (e.g., Nicolas and Bromwich 2011). It is also notable that the PPN differences are confined to the coastal margins and that the magnitude of the positive differences in SAT and PPN (which reach as much as $5^{\circ} \mathrm{C}$ and $1 \mathrm{~mm} \mathrm{day}^{-1}$ ) are considerably larger than the 

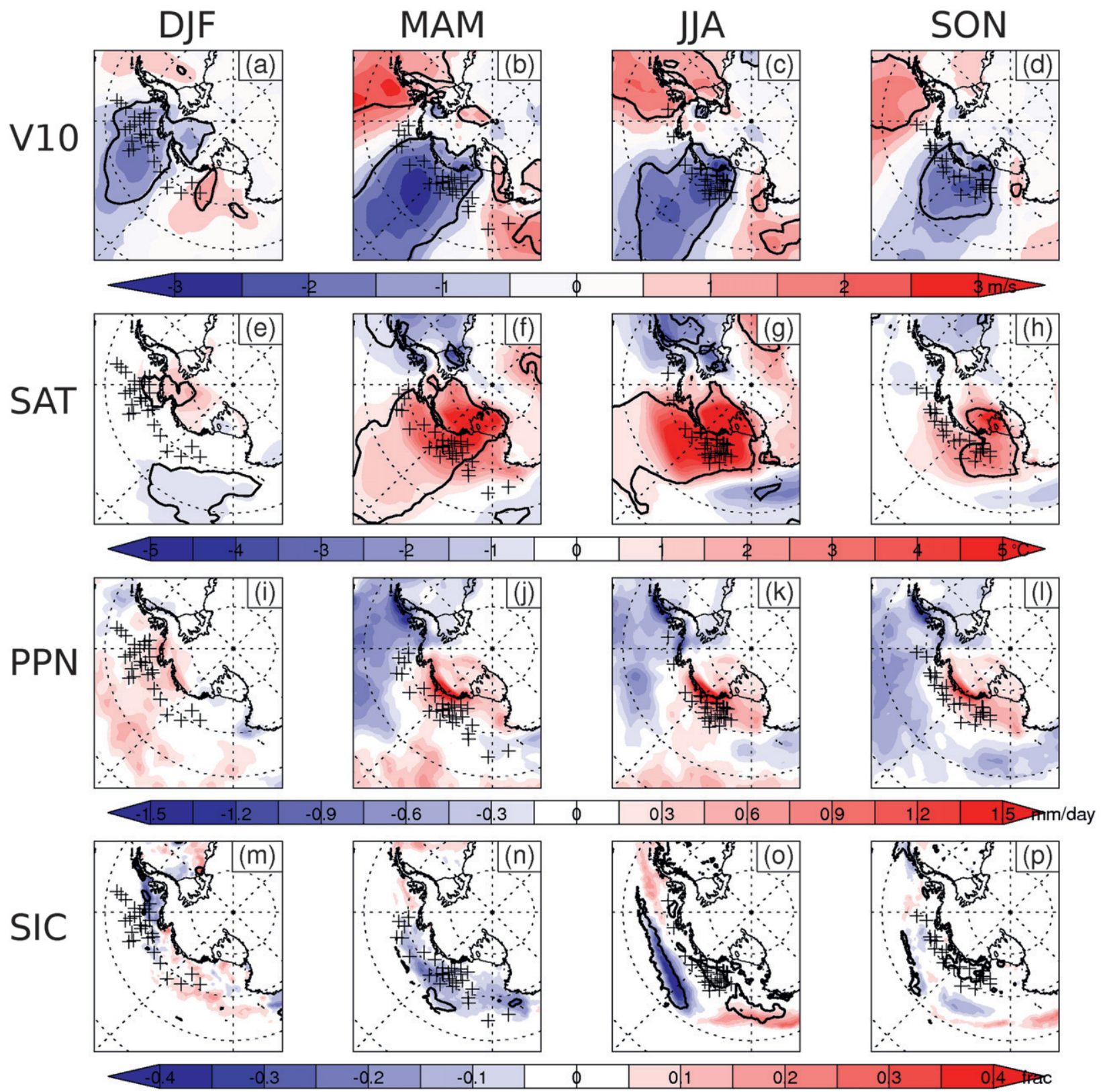

FIG. 6. Seasonal differences of (a)-(d) V10 $\left(\mathrm{m} \mathrm{s}^{-1}\right)$, (e)-(h) 2-m SAT $\left({ }^{\circ} \mathrm{C}\right)$, (i)-(l) PPN (mm day $\left.{ }^{-1}\right)$, and (m)-(p) SIC (fraction of unit area of sea ice) for ERA-Interim for the period 1979-2011 based on ABSL longitude [computed by evaluating the composite difference between the lower and upper quartiles ( $8 \mathrm{yr}$ each) classified according to the seasonal ABSL longitude]. Panels from left to right are for summer (DJF), autumn (MAM), winter (JJA), and spring (SON). The lower minus the upper quartile difference in ABSL longitude is positive when the ABSL is farther west. The plus sign indicates the location of the ABSL for each year. Statistically significant differences between the upper and lower quartiles at the $<5 \%$ level are indicated by the heavy black line.

negative differences. This is perhaps consistent with the approximately $3 \mathrm{~m} \mathrm{~s}^{-1}$ strengthening of the northerly flow exceeding that of any enhancement of the southerly flow, as well as with the extended sea ice coverage during winter (characterized by relatively cold conditions) providing a marked contrast with the advection of warm maritime air. A dipole of significant difference in SIC during winter is observed with values around $20 \%$ greater $(30 \%$ smaller) over the Ross Sea (Amundsen Sea) when the ABSL is farther west.

During spring, differences based on ABSL longitude are broadly similar to those described for winter and autumn but weaker and smaller in extent. The weaker significant differences during this season could be due 

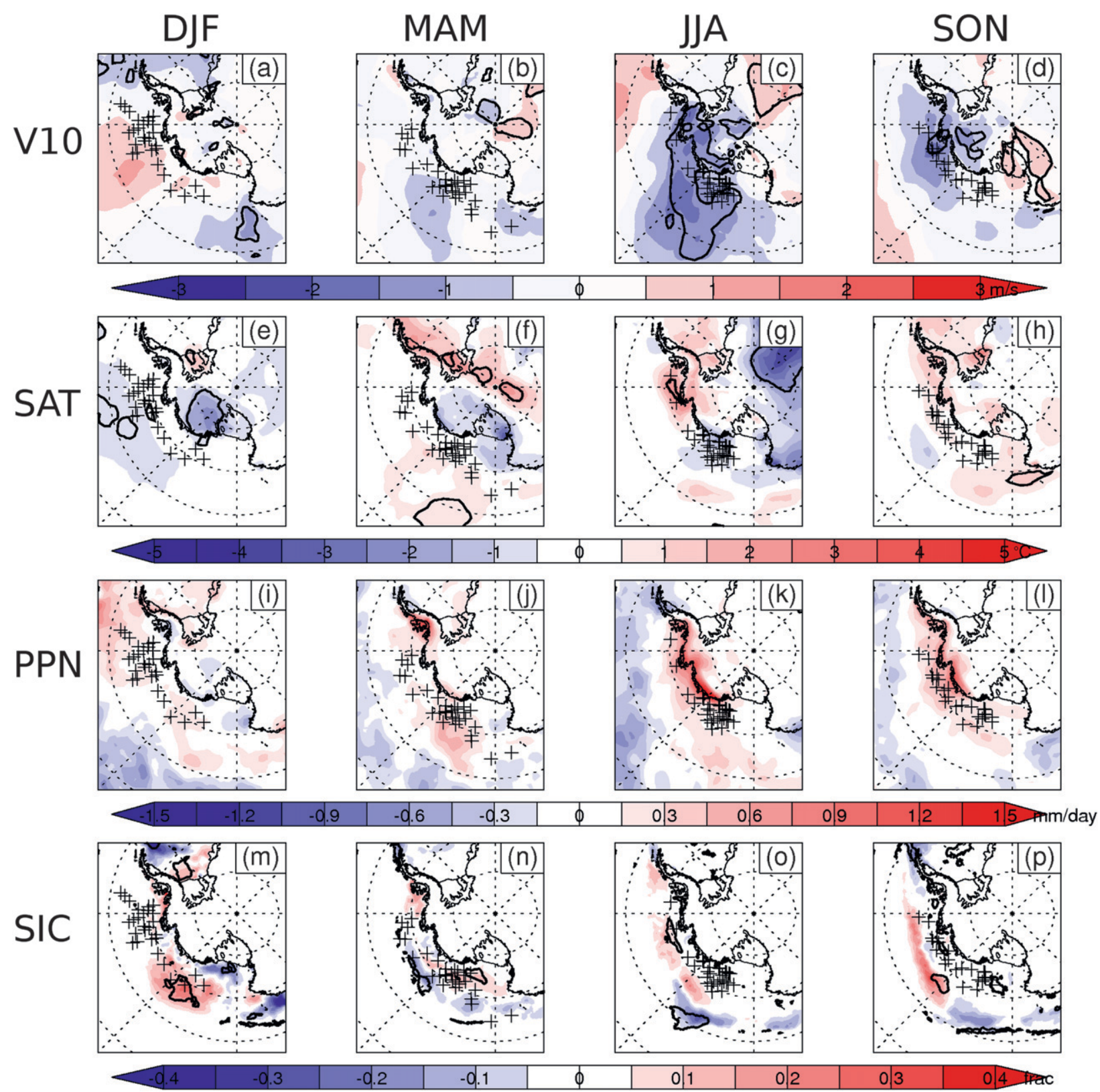

FIG. 7. As in Fig. 6 but showing the seasonal differences based on the ABSL relative central pressure. The lower minus the upper quartile difference in ABSL longitude is positive when the ABSL is deeper.

to the location of the ABSL varying widely with longitude, as evident from the plus symbols that mark its location for each year (as well as from Figs. 4 and 5), which may act to smooth out marked changes. During summer, significant differences in V10 are located farther eastward, consistent with the ABSL generally being confined to the Bellingshausen Sea during this season (cf. Fig. 5), but accompanying differences in SAT, PPN, and SIC are weak and limited in extent. Finally, it is notable that large statistically significant differences in V10 are observed over the peninsula and surrounding ocean during autumn, winter and spring. This perhaps reflects the climatological wavenumber-3 pattern (Raphael 2004), with a ridge located over the Bellingshausen Sea when the ABSL is located far west over the Ross Sea, which results in a strengthening of the southerly flow causing lower regional SAT and PPN and increasing SIC (although changes in PPN and SIC are not significant). As the ABSL moves eastward then the peninsula will experience northerly flow and the climate anomalies will be reversed. 
In Fig. 7, significant differences based on ABSL relative central pressure are for the most part smaller in both size and extent to those seen in Fig. 6. Only winter and spring show significant differences in V10 over parts of West Antarctica and the surrounding ocean. The most marked differences occur during winter, reflecting a strengthening of northerly flow over the ABS and Ross Sea of up to $1.5 \mathrm{~m} \mathrm{~s}^{-1}$ between the upper and lower quartiles when the ABSL relative central pressure is deeper. This results in intrusions of marine air causing increased PPN over the coastal margins of West Antarctica and higher (lower) SATs over Ellsworth Land (Marie Byrd Land), although only a small region of higher SATs is significant. The difference in SIC is not statistically significant, and moreover shows an increase over the Amundsen Sea, which is inconsistent with the strengthened northerly winds. Qualitatively similar differences are observed during spring. Significant differences based on relative central pressure are probably largest during winter owing to the ABSL position being fairly well constrained and relatively westward, again, as evident from the plus symbols and Figs. 4 and 5. Conversely, during summer when the ABSL position is relatively eastward, as the ABSL deepens the region of enhanced northerly (southerly) flow along its eastward (westward) flank is pushed eastward over the Antarctic Peninsula and Weddell Sea (Amundsen Sea). The corresponding differences in climate are consistent, showing decreased SAT and PPN over West Antarctica and increased SIC in the western Amundsen Sea and eastern Ross Sea, although these changes are not statistically significant.

\section{CMIP5 model representation of the ABSL and West Antarctic climate}

\section{a. Model representation of the ABSL}

In this section we assess the representation of the mean annual cycle of ABSL longitude (Fig. 8) and relative central pressure (Fig. 9) in each of the 17 CMIP5 models examined by validating against ERA-Interim for the 27 -yr period $1979-2005$. We show the \pm 1 standard error of the mean (which is sensitive to the sample sizei.e., the number of realizations) as a measure of the uncertainty of the mean value. This is used to determine months when differences between model and reanalysis are statistically significant, which is indicated by filled red circles. Significance is tested using a two-sided Student's $t$ test (at the $<5 \%$ level assuming 27 degrees of freedom). To make a quantitative comparison between the models we compute the rms deviation (RMSD) over all 12 months between the model mean and the reanalysis mean as a single measure of skill. The RMSD is displayed in the bottom-right corner of each panel in Figs. 8 and 9 and in Table 1. For reference, an RMSD value of $10^{\circ}$ of longitude is equal to $\sim 380 \mathrm{~km}$ at latitude $70^{\circ} \mathrm{S}$. The corresponding multimodel mean (Figs. $8 \mathrm{r}$ and 9r) is computed by averaging the mean and standard error of all 17 models. (Owing to the shorter period the annual cycle for ERA-Interim in Figs. 8 and 9 differs slightly from that shown earlier in Fig. 4.)

Figure 8 shows a mixed response in the model representation of the annual cycle of ABSL longitude. All 10 (9) of the models that show a statistically significant misrepresentation of the ABSL longitude in May (June) show an eastward bias (i.e., they underestimate the ABSL westward shift during these months). This problem is apparent in models such as HadGEM2-CC and MPI-ESM-LR (Table 1), which show the eastward bias occurs throughout winter. Conversely, all 10 of the models that show a statistically significant misrepresentation of the ABSL longitude in January show a westward bias; that is, they underestimate the ABSL eastward shift during this month. This problem is apparent in models, such as GISS-E2-H and MIROC4h, that also show the westward bias extends throughout summer. In the worst cases, models such as CSIRO-Mk3.6.0, HadCM3, and IPSL-CM5A-LR show both a significant eastward bias in winter and a westward bias in summer of up to $40^{\circ}$ (equivalent to $\sim$ two standard deviations of the reanalysis, see Fig. 4), such that the seasonal cycle of the ABSL longitudinal migration is reversed. This is evident by their high RMSD values, for example, $22.6^{\circ}$ for CSIRO-Mk3.6.0, $18.1^{\circ}$ for HadCM3, and $14.3^{\circ}$ for IPSLCM5A-LR. The model with one of the highest RMSD values of $21.7^{\circ}$ (INM-CM4) is characterized by a significant westward bias throughout most (eight months) of the year whereas the model with the lowest RMSD value of $6.5^{\circ}$ (CCSM4) largely captures both the westward migration of the ABSL from summer to winter and its return from winter to summer. The multimodel mean shows a reasonable agreement with a relatively low RMSD value $\left(9.0^{\circ}\right)$, although the seemingly good agreement is largely attributed to cancellations between the positive and negative biases in different models.

Figure 9 shows that there is a better representation of the annual cycle of ABSL relative central pressure compared to that of longitudinal position. All models except MIROC-ESM-CHEM are broadly able to capture the deepening of the ABSL over autumn and winter and its weakening over spring and summer. During winter four of the models (CCSM4, GISS-E2-H, MRICGCM3, and NorESM1-M) have at least one month with a significant negative bias in relative central pressure, with three of them showing the bias continuing into 

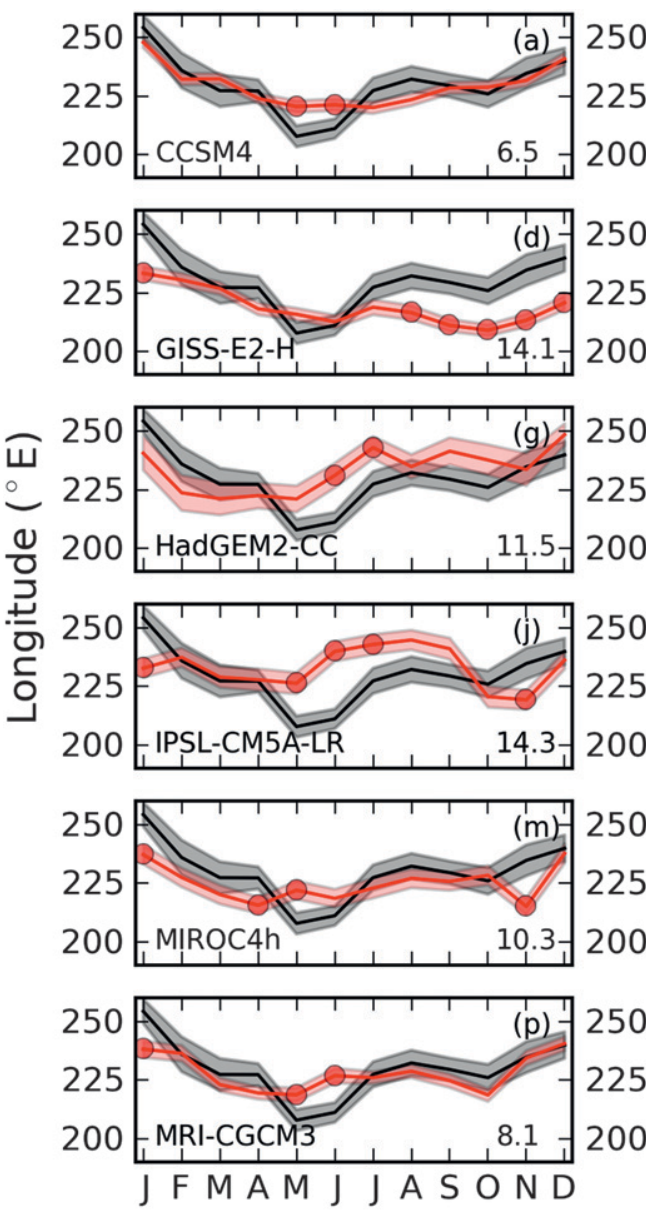
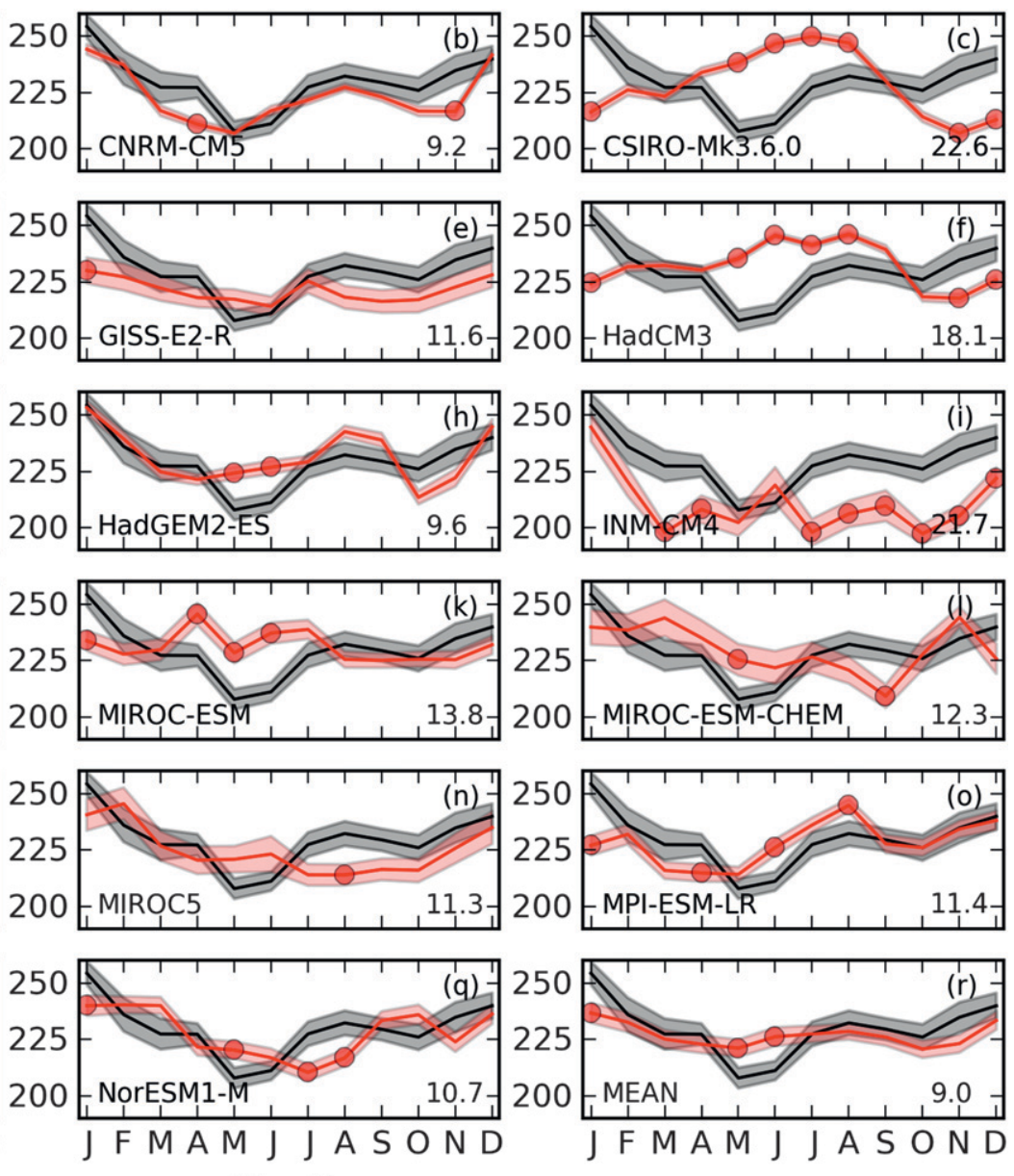

Month

FIG. 8. Mean annual cycle of the monthly ABSL longitude $\left({ }^{\circ} \mathrm{E}\right)$ (thick red line) and \pm 1 standard error (red shading) for each CMIP5 model for the period from 1979 to 2005. The mean annual cycle of the monthly ABSL longitude (black line) and \pm 1 standard error (gray shading) for ERA-Interim for the period 1979-2005 are included for comparison. Months in which a particular model is significantly different from ERA-Interim (at the $<5 \%$ level) are indicated by a filled red circle. The model name is shown in the bottom-left corner of each panel. The annual rms deviation (RMSD) for each model relative to ERA-Interim is shown in the bottom-right corner of each panel. For reference, a RMSD value of $10^{\circ}$ of longitude is equal to $\sim 380 \mathrm{~km}$ at latitude $70^{\circ}$ S. The panel labeled "MEAN" shows the multimodel mean of the 17 models.

spring. Indeed, MRI-CGCM3 is the model with the highest RMSD value $(2.46 \mathrm{hPa})$ and shows a significant negative bias in all months except February and March. Conversely, during winter four of the models (MIROC4h, MIROC-ESM, CSIRO-Mk3.6.0, and MIROC-ESMCHEM) have at least one month with a significant positive bias in relative central pressure, with all of them showing the bias continuing into spring. The HadGEM2ES and INM-CM4 models, which have the lowest RMSD values ( 0.64 and $0.70 \mathrm{hPa}$, respectively), capture the relative central pressure well, with INM-CM4 being the only model to have an annual cycle that is in statistical agreement with the reanalysis for all 12 months (although conversely it had the most number of months characterized by significant biases in ABSL longitude).
The best representation of the seasonal cycle is found in the multimodel mean which has the lowest RMSD value of $0.50 \mathrm{hPa}$.

It is evident that no one model is able to simulate both the annual cycle of relative central pressure and longitude with reasonable accuracy, making it difficult to assess their skill in representing the ABSL. For example, as shown in Table 1, CCSM4 is ranked first at simulating longitude (RMSD of $6.5^{\circ}$ ) but is only ranked seventh at simulating relative central pressure (RMSD of $0.86 \mathrm{hPa}$ ). Similarly, HadGEM2-ES is ranked first at simulating relative central pressure (RMSD of $0.64 \mathrm{hPa}$ ) and ranked fourth at simulating longitude (RMSD of $9.6^{\circ}$ ). To assess these two quantities together we plot their respective RSMD values against each other in Fig. 10. From this it is 

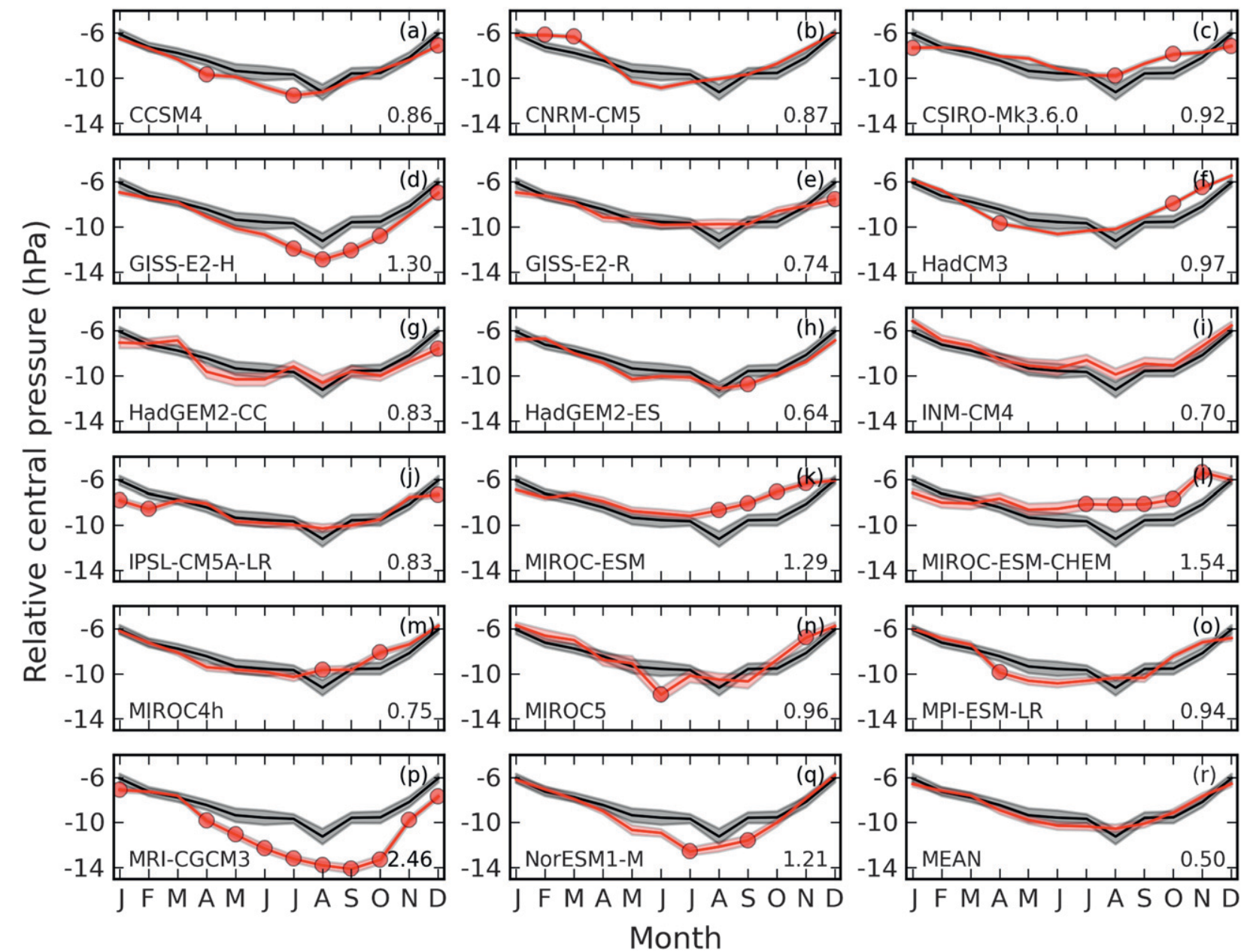

FIG. 9. As in Fig. 8 but for the ABSL relative central pressure (hPa).

apparent, with the exception of the three outliers (MRICGCM3, CSIRO-Mk3.6.0, and INM-CM4), that biases in longitude and relative central pressure broadly tend to increase together. We also note that the multimodel mean provides a good representation of the annual cycle of the ABSL.

\section{b. Model representation of West Antarctic climate}

In conjunction with our earlier results, these findings suggest that the majority of CMIP5 models have difficulty in realistically simulating the recent climate of West Antarctica. This is confirmed in Fig. 11, which compares seasonal biases of SAT and sea ice extent (with respect to ERA-Interim) between the worstperforming and best-performing models in terms of their representation of the ABSL annual cycle (with values closer to zero indicating that the model's seasonal mean is closer to the reanalysis). However, we firstly note that Fig. 11 shows that the model biases in SAT over sea ice are often sharply contrasted to those over the open ocean and land. A plausible explanation for this is that factors such as the misrepresentation of atmosphere-ice radiative and heat fluxes or surface inversion strength result in a general difficulty for the models to simulate SAT over sea ice. For this reason we only concentrate on SAT biases over land, which, as we show, appear to respond more in line with the representation of the circulation. We further note that Bracegirdle and Marshall (2012) show that ERA-Interim is itself characterized by a cold bias of a few degrees when compared to coastal stations (which they attribute to orography height errors associated with coarse resolution), while, as its SIE field is based on daily observations, it is representative of actual conditions.

Figure 10 and Table 1 shows that CSIRO-Mk3.6.0 is the worst-performing model examined in terms of the representation of longitudinal position, with Fig. 8 showing that it is characterized by a pronounced eastward (westward) bias in winter (summer). We note from Fig. 6 that we expect this to be related to colder 


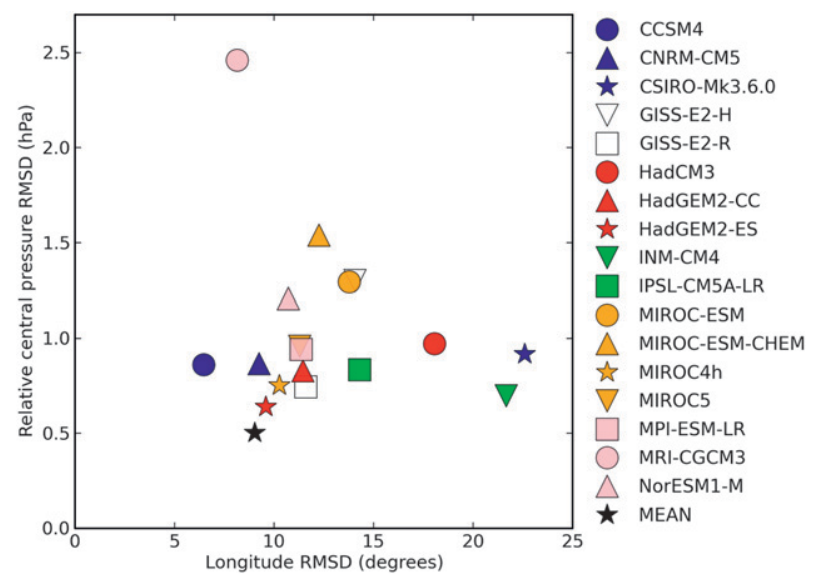

FIG. 10. Scatterplot of the annual rms deviation (RMSD) for each CMIP5 model relative to ERA-Interim of ABSL relative central pressure $(\mathrm{hPa})$ and longitude $\left({ }^{\circ}\right)$ for the period 1979-2005. For reference, an RMSD value of $10^{\circ}$ of longitude is equal to $\sim 380 \mathrm{~km}$ at latitude $70^{\circ} \mathrm{S}$. The symbol labeled "MEAN" shows the multimodel mean of the 17 models.

(warmer) SATs over the West Antarctic ice sheet (WAIS) in winter (summer) and increased SIC in the ABS and eastern sector of the Ross Sea in winter, with the changes in summer weaker and absent of significant anomalies in SIC. Comparison with Fig. 11 shows that such biases are qualitatively consistent with those of the model, which is characterized by a strong cold bias (up to $-10^{\circ} \mathrm{C}$ ) over the WAIS and anomalously extended SIE in the eastern sector of the Ross Sea in winter, and a weaker warm bias over the WAIS in summer. Figure 10 and Table 1 show that MRI-CGCM3 is the worstperforming model examined in terms of the representation of relative central pressure, with Fig. 9 showing that it is characterized by a marked negative bias in winter and spring. We note from Fig. 7 that we expect this to be related to slightly warmer SATs over the WAIS, although only the change in winter is significant. Comparison with Fig. 11 shows that such biases are qualitatively consistent with those of the model, which is characterized by a weak warm bias (up to $4^{\circ} \mathrm{C}$ ) over the WAIS in winter. We further note that, although it is difficult to quantify the expected influence of relative central pressure on SIC from Fig. 7 (owing to the lack of significant differences), the model bias in SIE is consistent with an anomalously deep ABSL during these seasons, that is, anomalously reduced (extended) SIE in the ABS (Ross Sea) sector. Finally, Fig. 10 and Table 1 show that one of the best-overall-performing models examined in terms of representing both the longitudinal position and relative central pressure is CCSM4 (see also Figs. 8 and 9). We therefore expect this model to have the smallest seasonal biases of SAT and
SIE. Comparison with Fig. 11 shows that this is indeed the case for SAT, with the model characterized by relatively small biases in SAT over the WAIS. However, Fig. 11 also suggests that, although this model broadly captures the shape of the SIE (including the localized northward extension seen around $200^{\circ} \mathrm{E}$ in winter and spring), in all seasons it actually systematically overestimates the SIE in the ABS and Ross Sea sectors.

\section{Discussion and conclusions}

In this study, we present a new method for defining the Amundsen-Bellingshausen Seas low in terms of the central pressure relative to the regionally averaged background pressure. In doing so, we remove much of the contribution from large-scale variability (e.g., the SAM) that is present within the actual central pressure (see Table 2). The residual index (termed the "relative central pressure") provides a more accurate measurement of the regional pressure gradient, thus allowing a more precise influence of the ABSL on the regional climate of West Antarctica to be determined. This relative central pressure index indicates that the ABSL itself is deepest (with increased meridional flow) during winter and shallower in summer. The annual cycle of longitudinal position is insensitive to whether the ABSL is specified according to relative or actual central pressure, and shows the ABSL shifting westward from $\sim 250^{\circ}$ to $\sim 220^{\circ} \mathrm{E}$ between summer and winter, in agreement with earlier studies.

We demonstrate that ABSL variability, and in particular its longitudinal position, plays an important role in controlling the surface climate over West Antarctica and the surrounding ocean by quantifying its influence on the 10-m meridional wind velocity, near-surface $(2 \mathrm{~m})$ air temperature, precipitation, and sea ice concentration. The controlling influence of ABSL relative central pressure is less marked, although this is thought to be due to variability in longitude masking its impact; that is, the effect of relative central pressure is most apparent when the ABSL is "locked in" to a confined location (low variability in longitude) such as in winter.

The high sensitivity of the West Antarctic climate to the ABSL longitudinal position implies that it is particularly important for models to capture longitudinal position in order to realistically simulate the climate of West Antarctica and, furthermore, that the importance of the representation of relative central pressure is secondary. However, investigation of 17 CMIP5 climate models run with historical forcing showed that the majority of the models have statistically significant and systematic biases that are more pronounced in terms of 

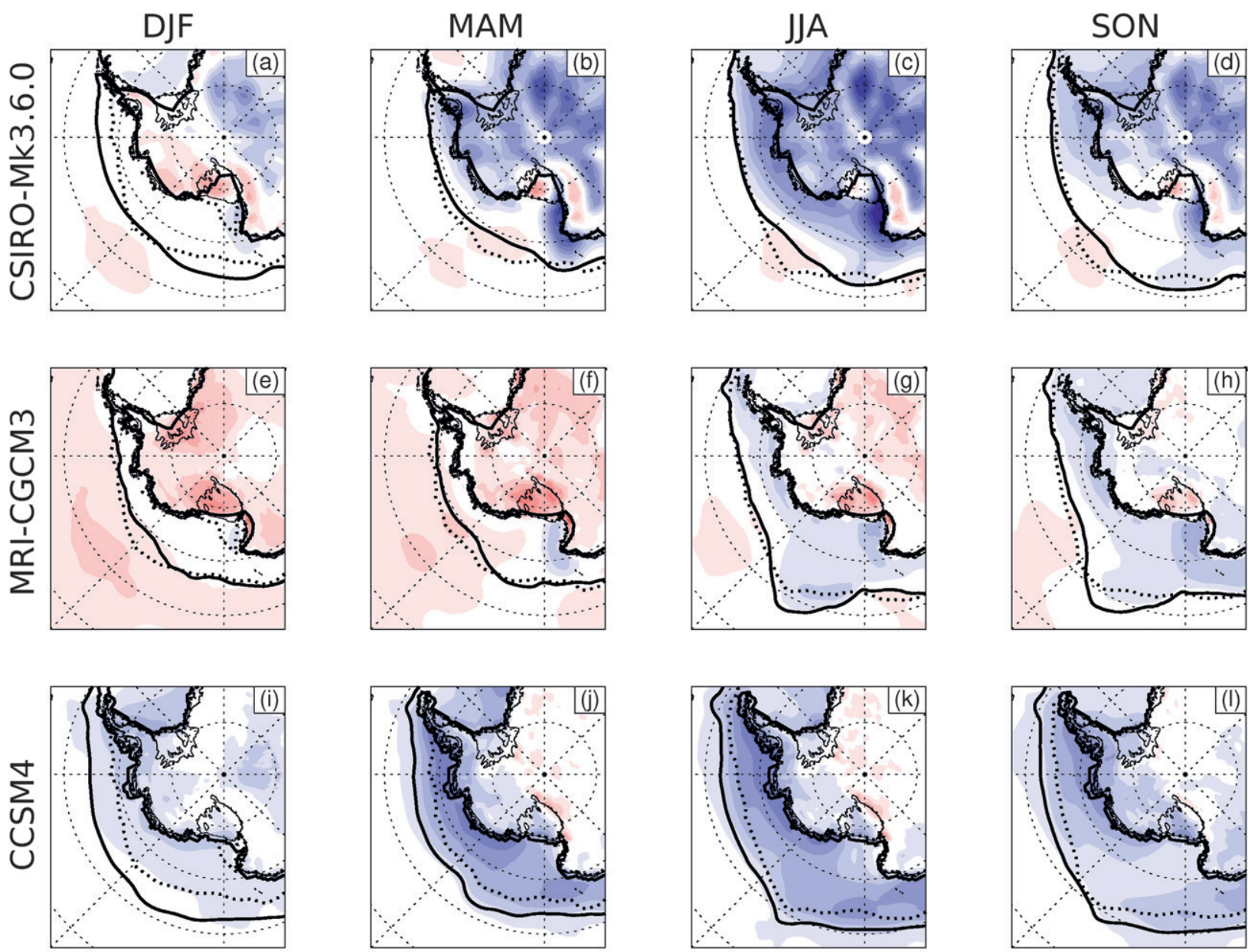

FIG. 11. Seasonal biases (relative to ERA-Interim) of SAT ( ${ }^{\circ} \mathrm{C}$, colors) and SIE (lines) for (a)-(d) CSIRO-Mk3.6.0, (e)-(h) MRICGCM3, and (i)-(1) CCSM4 for 1979-2005. Panels from left to right are for summer (DJF), autumn (MAM), winter (JJA), and spring (SON). The solid (dotted) lines indicate the model (ERA-Interim) SIE (defined as where the SIC fraction is at least 0.15). CSIRO-Mk3.6.0 (MRI-CGCM3) was the worst performing of the CMIP5 models examined in terms of representing the longitudinal position (relative central pressure) of the ABSL. CCSM4 was one of the best-performing CMIP5 models examined in terms of representing both the longitudinal position and relative central pressure of the ABSL.

the representation of longitudinal position than relative central pressure. For example, the majority of models show 1) a significant eastward bias during May/June, which many show extending throughout winter (although not always at a statistically significant level) and 2) a significant westward bias in January. A few of the models even simulate an ABSL longitudinal migration that is the reverse of reality: that is, that incorrectly the ABSL shifts eastward in winter and westward in summer. In terms of relative central pressure, although the models are broadly able to capture that the ABSL is deeper in winter and shallower in summer, the majority of them show a significant bias in at least one winter month. This is more or less evenly split in terms of negative and positive biases, which continue into spring (although, again, not always at a statistically significant level).

The implications of this are, indeed, that the majority of CMIP5 models will have a correspondingly poor representation of West Antarctic climate due to difficulties in representing the ABSL annual cycle, particularly its longitudinal position. Investigation of the seasonal biases in West Antarctic climate of some of the bestperforming and worst-performing models was consistent with this. However, the realistic simulation of the seasonal cycle of sea ice presents a number of problems for climate models besides the correct representation of the atmosphere component, namely the correct representation of ocean currents and the complicated thermodynamical 
and dynamical processes within the ice pack (e.g., McLaren et al. 2006). Turner et al. (2013a) showed that the majority of the CMIP5 models have a seasonal cycle of sea ice extent that differs markedly from the observations, whereas Zunz et al. (2012) showed that the CMIP5 multimodel mean underestimates (overestimates) the SIE in the ABS and Ross Sea sectors over the period from 1979 to 2005 in February (September), which are the months where the sea ice cover reaches its minimum (maximum). We note that from Figs. 8 and 9 both February and September are months characterized by a relatively good representation of the annual cycle of the ABSL in CMIP5, consistent with the suggestion that, even when the ABSL is correctly represented, considerable sea ice errors can still exist.

Although the CMIP5 models show a mixed response in the representation of the ABSL annual cycle, the multimodel mean produces a reasonable representation. This result mirrors the findings of Connolley and Bracegirdle (2007), who demonstrated that the CMIP3 multimodel mean generally provided a better estimate of Antarctic climate than any individual model. Future work will involve investigating the reasons why the CMIP5 representation of the annual cycle of the ABSL is mixed and, in particular, focusing on the representation of the midtropospheric planetary waves, which Turner et al. (2013b) showed is linked to the longitudinal position of the ABSL.

Acknowledgments. The valuable comments of the three anonymous reviewers contributed tremendously to the improvement of the original manuscript. This work was undertaken as part of the Polar Science for Planet Earth Programme of the British Antarctic Survey, supported by the Natural Environment Research Council of the United Kingdom. We acknowledge the World Climate Research Programme's Working Group on Coupled Modelling, which is responsible for CMIP, and we thank the climate-modeling groups (listed in Table 1 of this paper) for producing and making available their model output. For CMIP the U.S. Department of Energy's Program for Climate Model Diagnosis and Intercomparison provides coordinating support and led development of software infrastructure in partnership with the Global Organization for Earth System Science Portals. Many thanks are given to T. Bracegirdle for valuable discussions on this work, and also to H. Roscoe and J. King for advice on statistical analysis.

\section{REFERENCES}

Bracegirdle, T. J., and G. J. Marshall, 2012: The reliability of Antarctic tropospheric pressure and temperature in the latest global reanalyses. J. Climate, 25, 7138-7146.
Bromwich, D. H., J. P. Nicolas, and A. J. Monaghan, 2011: An assessment of precipitation changes over Antarctica and the Southern Ocean since 1989 in contemporary global reanalyses. J. Climate, 24, 4189-4209.

,,,-- M. A. Lazzara, L. M. Keller, G. A. Weidner, and A. B. Wilson, 2013: Central West Antarctica among the most rapidly warming regions on Earth. Nat. Geosci., 6, 139-145, doi:10.1038/ngeo1671.

Comiso, J. C., 1999: Bootstrap sea ice concentrations from NIMBUS-7 SMMR and DMSP SMM/I-SSMIS. National Snow and Ice Data Center. Digital media. [Available online at http://nsidc.org/data/docs/daac/nsidc0079_bootstrap_seaice. gd.html.]

Connolley, W. M., and T. J. Bracegirdle, 2007: An Antarctic assessment of IPCC AR4 coupled models. Geophys. Res. Lett., 34, L22505, doi:10.1029/2007GL031648.

Dee, D. P., and Coauthors, 2011: The ERA-Interim reanalysis: Configuration and performance of the data assimilation scheme. Quart. J. Roy. Meteor. Soc., 137, 553-597, doi:10.1002/qj.828.

Ding, Q., E. J. Steig, D. S. Battisti, and M. Küttel, 2011: Winter warming in West Antarctica caused by central tropical Pacific warming. Nat. Geosci., 4, 398-403, doi: 10.1038/ngeo1129.

Fogt, R. L., D. H. Bromwich, and K. M. Hines, 2011: Understanding the SAM influence on the South Pacific ENSO teleconnection. Climate Dyn., 36, 1555-1576.

— J. M. Jones, and J. Renwick, 2012a: Seasonal zonal asymmetries in the southern annular mode and their impact on regional temperature anomalies. J. Climate, 25, 62536270.

, A. J. Wovrosh, R. A. Langen, and I. Simmonds, 2012b: The characteristic variability and connection to the underlying synoptic activity of the Amundsen-Bellingshausen Seas low. J. Geophys. Res., 117, D07111, doi:10.1029/2011JD017337.

Holland, P. R., and R. Kwok, 2012: Wind-driven trends in Antarctic sea-ice drift. Nat. Geosci., 5, 872-875, doi:10.1038/ngeo1627.

Küttel, M., E. J. Steig, Q. Din, A. J. Monaghan, and D. S. Battisti, 2012: Seasonal climate information preserved in West Antarctic ice core water isotopes: Relationships to temperature, large-scale circulation, and sea ice. Climate Dyn., 39, 18411857, doi:10.1007/s00382-012-1460-7.

Kwok, R., and J. C. Comiso, 2002: Spatial patterns of variability in Antarctic surface temperature: Connections to the Southern Hemisphere annular mode and the Southern Oscillation. Geophys. Res. Lett., 29 (14), doi:10.1029/2002GL015415.

Lachlan-Cope, T. A., W. M. Connolley, and J. Turner, 2001: The role of the non-axisymmetric Antarctic orography in forcing the observed pattern of variability of the Antarctic climate. Geophys. Res. Lett., 28, 4111-4114.

Lefebvre, W., H. Goosse, R. Timmermann, and T. Fichefet, 2004: Influence of the southern annular mode on the sea ice-ocean system. J. Geophys. Res., 109, C09005, doi:10.1029/2004JC002403.

Marshall, G. J., 2003: Trends in the southern annular mode from observations and reanalysis. J. Climate, 16, 4134-4143.

Massom, R. A., S. E. Stammerjohn, W. Lefebvre, S. A. Harangozo, N. Adams, T. A. Scambos, M. J. Pook, and C. Fowler, 2008: West Antarctic Peninsula sea ice in 2005: Extreme ice compaction and ice edge retreat due to strong anomaly with respect to climate. J. Geophys. Res., 113, C02S20, doi:10.1029/ 2007JC004239.

McLaren, A. J., and Coauthors, 2006: Evaluation of the sea ice simulation in a new coupled atmosphere-ocean climate model (HadGEM1). J. Geophys. Res., 111, C12014, doi:10.1029/ 2005JC003033. 
Monaghan, A. J., and Coauthors, 2006: Insignificant change in Antarctic snowfall since the International Geophysical Year. Science, 313, 827-831.

, D. H. Bromwich, W. Chapman, and J. C. Comiso, 2008: Recent variability and trends of Antarctic near-surface temperature. J. Geophys. Res., 113, D04105, doi:10.1029/2007JD009094.

Nicolas, J. P., and D. H. Bromwich, 2011: Climate of West Antarctica and influence of marine air intrusions. J. Climate, 24, 49-67.

O’Donnell, R., N. Lewis, S. McIntyre, and J. Condon, 2011: Improved methods for PCA-based reconstructions: Case study using the Steig et al. (2009) Antarctic temperature reconstructions. J. Climate, 24, 2099-2115, doi:10.1175/2010JCLI3656.1.

Raphael, M. N., 2004: A zonal wave 3 index for the Southern Hemisphere. Geophys. Res. Lett., 31, L23212, doi:10.1029/ 2004GL020365.

Rayner, N. A., D. E. Parker, E. B. Horton, C. K. Folland, L. V. Alexander, D. P. Rowell, E. C. Kent, and A. Kaplan, 2003: Global analyses of sea surface temperature, sea ice, and night marine air temperature since the late nineteenth century. J. Geophys. Res., 108, 4407, doi:10.1029/2002JD002670.

Schneider, D. P., and E. J. Steig, 2008: Ice cores record significant 1940s Antarctic warmth related to tropical climate variability. Proc. Natl. Acad. Sci. USA, 105, 12154-12158.

- C. Deser, and Y. Okumura, 2012: An assessment and interpretation of the observed warming of West Antarctic in the austral spring. Climate Dyn., 38, 323-347, doi:10.1007/ s00382-010-0985-x.

Stammerjohn, S. E., D. G. Martinson, R. C. Smith, X. Yuan, and D. Rind, 2008: Trends in Antarctic annual sea ice retreat and advance and their relation to El Niño-Southern Oscillation and southern annular mode variability. J. Geophys. Res., 113, C03S90, doi:10.1029/2007JC004269.

Steig, E. J., D. P. Schneider, S. D. Rutherford, M. E. Mann, J. C. Comiso, and D. T. Shindell, 2009: Warming of the Antarctic ice-sheet surface since the 1957 International Geophysical Year. Nature, 457, 459-462, doi:10.1038/nature07669.

Taylor, K. E., R. J. Stouffer, and G. A. Meehl, 2012: An overview of CMIP5 and the experiment design. Bull. Amer. Meteor. Soc., 93, 485-498.
Thomas, E. R., G. J. Marshall, and J. R. McConnell, 2008: A doubling in snow accumulation in the western Antarctic Peninsula since 1850. Geophys. Res. Lett., 35, L01706, doi:10.1029/2007GL032529.

Thompson, D. W. J., and J. M. Wallace, 2000: Annular modes in the extratropical circulation. Part I: Month-to-month variability. J. Climate, 13, 1000-1016.

Trenberth, K. E., 1997: The definition of El Niño. Bull. Amer Meteor. Soc., 78, 2771-2777.

Turner, J., 2004: The El Niño-Southern Oscillation and Antarctica. Int. J. Climatol., 24, 1-31.

_ - and Coauthors, 2009: Non-annular atmospheric circulation change induced by stratospheric ozone depletion and its role in the recent increase of Antarctic sea ice extent. Geophys. Res. Lett., 36, L08502, doi:10.1029/2009GL037524.

— T. J. Bracegirdle, T. Phillips, G. J. Marshall, and J. S. Hosking, 2013a: An initial assessment of Antarctic sea ice extent in the CMIP5 models. J. Climate, 26, 1473-1484.

_ , T. Phillips, J. S. Hosking, G. J. Marshall, and A. Orr, 2013b: The Amundsen Sea low. Int. J. Climatol., 33, 1818-1829.

van Loon, H., 1967: The half-yearly oscillations in middle and high southern latitudes and the coreless winter. J. Atmos. Sci., 24, $472-486$.

Vaughan, D. G., J. L. Bamber, M. Giovinetto, J. Russell, and A. P. R. Cooper, 1999: Reassessment of net surface mass balance in Antarctica. J. Climate, 12, 933-946.

_ , G. J. Marshall, W. M. Connolley, J. C. King, and R. Mulvaney, 2001: Devil in the detail. Science, 293, 1777-1779.

Walsh, K. J. E., I. Simmonds, and M. Collier, 2000: Sigmacoordinate calculation of topographically forced baroclinicity around Antarctica. Dyn. Atmos. Oceans, 33, 1-29, doi:10.1016/ S0377-0265(00)00054-3.

Zunz, V., H. Goosse, and F. Massonnet, 2012: How does internal variability influence the ability of CMIP5 models to reproduce the recent trend in Southern Ocean sea ice extent? Cryosphere Discuss., 6, 3539-3573, doi:10.5194/tcd-6-3539-2012.

Zwally, H. J., J. C. Comiso, C. L. Parkinson, D. J. Cavalieri, and P. Gloersen, 2002: Variability of Antarctic sea ice 1979-1998. J. Geophys. Res., 107 (C5), doi:10.1029/2000JC000733. 